\title{
Effects of cyclosporin-a on rat skeletal biomechanical properties
}

\author{
Yixin Chen", Xin Zheng, Rui Zou and Junfei Wang
}

\begin{abstract}
Background: Cyclosprin A ( $C S A)$ has been widely used clinically to treat the patients who have undergone organ transplantation or acquired autoimmune disease. The purpose of this study is to determine the effects of three different doses of CsA (1.5, 7.5, $15 \mathrm{mg} / \mathrm{kg}$ body weight) on the skeletal biomechanical proprieties at different anatomic sites in rats.
\end{abstract}

Methods: Fifty-six male 3-month-old Wistar rats were divided into five groups. Eight rats were randomly chosen as the basal group, while the others were randomly distributed into four groups of 12 animals each. One group was used as controls and received daily subcutaneous injection of $1 \mathrm{ml}$ of saline solution; another three experimental groups were injected subcutaneously with CSA in a daily dose of $1.5,7.5$, and $15 \mathrm{mg} / \mathrm{kg}$ body weight respectively for 60 days. The bone biomechanical proprieties, the bone mineral density, as well as the trabecular bone architecture were measured at different anatomic sites, i.e. the lumbar vertebra, the middle femur shaft, and the proximal femur.

Results: CsA therapy at 7.5 and $1.5 \mathrm{mg} / \mathrm{kg}$ can significantly reduce the ultimate force, the ultimate stress and the energy absorption per unit of bone volume of the lumbar vertebra, with no effect on the middle femur. CsA therapy at $7.5 \mathrm{mg} / \mathrm{kg}$ can significantly reduce the ultimate force, the ultimate stress and the Young's modulus of the femoral neck, but not CsA at $1.5 \mathrm{mg} / \mathrm{kg}$. Furthermore, CsA therapy at 7.5 and $1.5 \mathrm{mg} / \mathrm{kg}$ can significantly reduce the bone mineral density of the lumber vertebra and the proximal femur, but have no effect on the middle femur. CsA therapy at 7.5 and $1.5 \mathrm{mg} / \mathrm{kg}$ can also significantly reduce the bone volume fraction of the proximal tibia and the lumber vertebra, but has no effect on the cortical thickness of the middle femoral shaft. In the 15 $\mathrm{mg} / \mathrm{kg}$ CsA group only one rat survived, and the kidney and liver histology of the survived rat showed extensive tissue necrosis.

Conclusion: Long-term use of CSA can weaken the biomechanical properties and thus increase the fracture rate of the lumbar vertebra and the proximal femur. However, CSA therapy has less effect on the middle femur shaft. The effects of CSA on skeleton are site-specific.

\section{Background}

Cyclosporin A (CsA) has been widely used clinically to prevent organ rejection in post-transplantation and to ameliorate the autoimmune disorders. However, since the patients usually receive a combination of several drugs, the isolated clinical effects of CsA on human skeleton are still unclear. Although it is increasingly believed that CsA can cause bone loss in humans [1,2], it is interestingly found that CsA monotherapy in renal transplantation patients

\footnotetext{
*Correspondence: chenyixin93@yahoo.com

Department of Orthopedics, Drum Tower Hospital of Nanjing, affiliated to the Medical School of Nanjing University, Zhongshan North Road, No.381, 210008, Nanjing, Jiangsu Province, PR China
}

can significantly increase lumbar bone mineral density $[3,4]$. Yet up to now, a correlation between the daily or accumulative dose of CsA and fracture frequency has not been established [5]. It remains to be found out whether long-term use of CsA will increase the fracture risk in humans.

There are numerous experimental studies evaluating the effects of CsA on the bone metabolism. Some in-vivo studies have demonstrated that CsA in the rats can induce high-turnover bone loss, resulting in an uncoupling of the dynamic bone remodeling cycle with resorption exceeding formation and leading to an ultimate loss of trabecular bone [6-8]. Bone histomorphometry in

\section{Biomed Central}

(C) 2011 Chen et al; licensee BioMed Central Ltd. This is an Open Access article distributed under the terms of the Creative Commons Attribution License (http://creativecommons.org/licenses/by/2.0), which permits unrestricted use, distribution, and reproduction in any medium, provided the original work is properly cited. 
these studies shows increased osteoclast number, increased parameters of bone formation, and decreased percent trabecular bone volume [6-8]. However, CsA dos not affect the absolute rate of cortical bone resorption at the organ level [9]. The effect of CsA on bone mineral metabolism is dependent on both the dose and the duration of administration $[10,11]$. Transforming growth factor-beta, alendronate, and raloxifene analog may have potential in modulating the deleterious bone effects of CsA $[7,12,13]$. The precise mechanisms involved in CsAinduced bone loss are still not well defined. Wada et al suggested that the bone resorption in CsA-treated rats may be activated by plasma parathyroid hormone (PTH) [6]. However, Epstein et al founded that PTH may not be essential for CsA-induced bone loss, and Buchinsky et al suggested that $\mathrm{T}$ lymphocytes appeared to be a prerequisite for the development of CsA-induced bone loss $[14,15]$.

Few studies have evaluated the effects of CsA on bone mechanical properties. As Jarvinen et al emphasized, we should not forget that the primary function of the skeleton is locomotion of the body and that only adequately rigid and strong bones make this vital function feasible [16]. It is thus important to evaluate the effects of CsA on bone mechanical properties. Warren et al. treated the rats with CsA for 14 consecutive days at a dose of $7 \mathrm{mg} / \mathrm{kg}$ body weight/day, and did not find alteration in biomechanical properties with respect to the failure torque and the stiffness of the femur diaphysis [17]. However, they reminded us that testing in torsion emphasizes cortical bone characteristics, and the short-term nature of treatment with this drug may have failed to significantly influence cortical bone [17]. It is still necessary to illuminate the detrimental effect of CsA on bone mechanical proprieties in rats.

In the present study, we hypothesized that the longterm use of CsA in the rats will damage the bone mechanical properties, and the detrimental effect of CsA on biomechanical properties is different in varied skeletal anatomy sites.

\section{Methods}

\section{Animals}

Fifty-six male 3-month-old Wistar rats (200 250 g) purchased from the Model Animal Research Center of Nanjing University were housed with free access to water and chow with constant 12-hour light-dark cycle environmental conditions. They were all acclimatized for 1 week before the experiment began. All animal experiments were approved by the Animal Study Committee of Nanjing University.

Eight rats were randomly chosen as the basal group and were sacrificed at the beginning of the injection protocol for the treated rats, while the others were randomly distributed into four groups of 12 animals each. One group was used as controls and received daily subcutaneous injection of $1 \mathrm{ml}$ of saline solution. Another three experimental groups were injected subcutaneously with CsA (Novartis Pharmaceuticals, Basel, Switzerland) in a daily dose of $1.5 \mathrm{mg} / \mathrm{kg}$ body weight, $7.5 \mathrm{mg} / \mathrm{kg}$ body weight, and $15 \mathrm{mg} / \mathrm{kg}$ body weight respectively $[8,11,18]$. The experimental period of the study extended over 60 days.

\section{Biochemical assay of blood and body weight measurement}

After sixty days of the CsA therapy, the rats were exsanguinated from the abdominal aorta under anesthesia to obtain serum for the determination of serum alanine aminotransferase (ALT), serum aspartate aminotransferase (AST), serum urea nitrogen (BUN), and serum creatinine $(\mathrm{Cr})$. The body weight was also measured [19].

\section{Evaluation of kidney and liver histologic changes}

For histological analysis of the rat's kidney and liver in $15 \mathrm{mg} / \mathrm{kg}$ CsA group, paraffin-embedded 6- $\mu \mathrm{m}$-thick sections were stained with hematoxylin and eosin [19].

\section{Bone mineral density and bone length measurement}

As we reported in our previous study [19], the $\mathrm{L}_{1-5}$ vertebra and the total femur were removed off the soft tissue, and the bone mineral density (BMD) of the $\mathrm{L}_{1-5}$ vertebra, the femur mid-diaphseal region (the middle two of the four equal regions of the femur length, Figure 1) and the proximal femur region (the proximal one of four equal regions of the femur length, Figure 1) were measured using dual-energy X-ray absorptiometry (Hologic QDR4000, USA). The lengths of humerus, tibia and femur were measured using vernier caliper.

\section{Mechanical testing}

The mechanical test was described in detail in our previous study [19]: the extrinsic parameters (the ultimate force, the stiffness and the energy absorption) were obtained directly from the load-deformation curves that were recorded continually in a computerized monitor and the intrinsic parameters (the ultimate stress, the Young's modulus and the energy absorption per unit of bone volume) can be computed from extrinsic parameters and geometric data. Briefly, a compression force was applied to the cylinder samples of the $\mathrm{L}_{2}$ body specimen at a rate of $2.5 \mathrm{~mm} /$ minute (Instron 3367); the $\mathrm{L}_{2}$ body cross sections were assumed to be elliptically shaped, two diameters, anterior-posterior (a) and leftright (b), of this cylinder were measured using vernier caliper and used to calculate the cross-sectional area (S) $(\mathrm{S}=\pi \mathrm{ab} / 4)$. A bending force was applied to the middle femur shaft at a speed of $5 \mathrm{~mm} /$ minute until fracture occurred; the femur cross sections were assumed to be elliptically shaped, the moment of inertia is $I=\pi\left[a b^{3}-\mid(a-\right.$ 


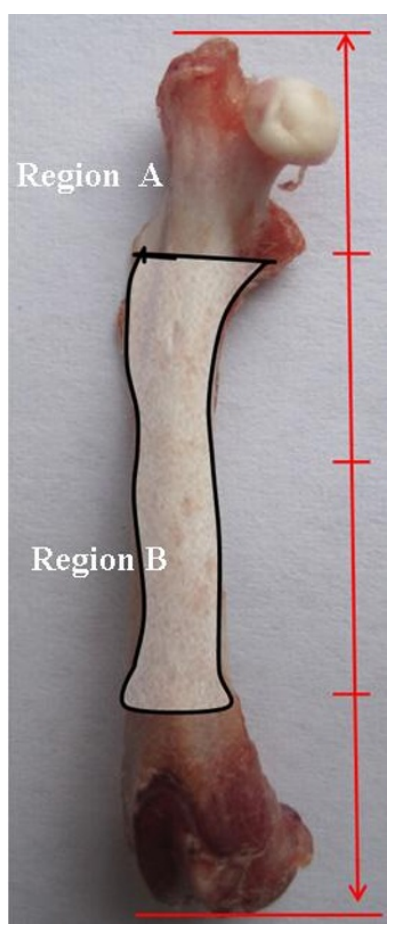

Figure 1 The region defined on the femur. Region $A$ : the proximal femur region, the proximal one of four equal regions of the femur length; Region B: the femur mid-diaphseal region, the middle two of the four equal regions of the femur length.

|2t)(b- $\left.\mid 2 t)^{3}\right] / 64:$ Where $a$ is the width of the cross section in the medial-lateral direction, $\mathrm{b}$ is the width in the anterior-posterior direction, and $t$ is the average cortical thickness. A cantilever bending force was applied perpendicularly to the femur neck at a speed of $5 \mathrm{~mm} /$ minute until fracture occurred; the femur neck cross sections were assumed to be elliptically shaped, the section modulus is $\mathrm{Wz}=\pi \mathrm{a}^{2} \mathrm{~b} / 32$ : Where $\mathrm{a}$ is the width of the cross section in the superior-inferior direction, and $b$ is the width in the anterior-posterior direction.

\section{Bone histomorphometry analyses}

The $\mathrm{L}_{4}$ vertebra body and the right proximal tibia metaphysis were removed off the soft tissue and fixed in 10\% phosphate-buffered formalin for $24 \mathrm{~h}$. The vertebrae and the tibia metaphyses were then dehydrated in ethanol, defatted in xylene, and embedded in methyl methacrylate. The frontal sections were cut at $4 \mu \mathrm{m}$ thickness with a microtome (Leica RM2155; Germany) and were stained with Goldner's trichrome for quantification of trabecular bone architecture. A semi-automatic image analysis system (Image-Pro Plus) was used to measure the bone volume fraction(\%), the trabecular number $(\# / \mathrm{mm})$, the trabecular thickness $(\mu \mathrm{m})$, and the trabecular separation $(\mu \mathrm{m})[20]$. The anterior-posterior cortical thickness of the middle femoral shaft was measured using vernier caliper [19].

\section{Statistical analysis}

All statistical analyses were carried out using SPSS v.13. The groups were compared by means of 1-way ANOVA (S-N-K) if the variances were homogeneous; but if not, Kruskal-Wallis test was used. The statistical differences were detected among the control group, $1.5 \mathrm{mg} / \mathrm{kg}$ CsA group and $7.5 \mathrm{mg} / \mathrm{kg}$ CsA group. All values were expressed as $\bar{X} \pm$ SD. Statistical significance was accepted at $\mathrm{P}<0.05$.

\section{Results}

\section{Effects of varying doses of CsA on kidney and liver function}

In the $15 \mathrm{mg} / \mathrm{kg}$ CsA group only one rat survived. The kidney and liver histology of the survived rat showed extensive tissue necrosis (Figure 2), and the serum ALT, AST, BUN and Cr levels were respectively 2.5, 2.8, 3, and 1.5 times of the averaged levels of the control group. In the $7.5 \mathrm{mg} / \mathrm{kg}$ CsA group, three rats died. One rat in the $1.5 \mathrm{mg} / \mathrm{kg}$ CsA group was excluded in our study due to a huge neck mass. No significant change in ALT, AST, BUN and $\mathrm{Cr}$ levels was observed among the control group, the $1.5 \mathrm{mg} / \mathrm{kg}$ CsA group and the $7.5 \mathrm{mg} / \mathrm{kg}$ CsA group (Table 1).

\section{The kidney and liver histology of the survived rat in 15 $\mathrm{mg} / \mathrm{kg}$ CsA group}

Only one rat survived in the $15 \mathrm{mg} / \mathrm{kg}$ CsA group. The kidney and liver histology of the survived rat showed tissue necrosis (Figure 2).

\section{Effects of varying doses of $\mathrm{CsA}$ on the bone length and the body weight}

No significant change in the bone length or the body weight was observed among the control group, the 1.5 $\mathrm{mg} / \mathrm{kg}$ CsA group and the $7.5 \mathrm{mg} / \mathrm{kg}$ CsA group (Figure 3).

Effects of varying doses of CsA on bone mineral density Compared with the control group, both the $1.5 \mathrm{mg} / \mathrm{kg}$ CsA group and $7.5 \mathrm{mg} / \mathrm{kg}$ CsA groups had statistically significant decreases in the BMD and BMC values of the lumber vertebra and the proximal femur, but had no significant changes in the BMD and BMC values of the middle femur. No significant differences in the values of the Area were obtained among the control group, 1.5 $\mathrm{mg} / \mathrm{kg}$ CsA group and $7.5 \mathrm{mg} / \mathrm{kg}$ CsA group (Table 2).

\section{Effects of varying doses of CsA on bone mechanical properties}

The second lumbar vertebra displayed statistically significant lower values of the ultimate force, the ultimate stress and the energy absorption per unit of bone 


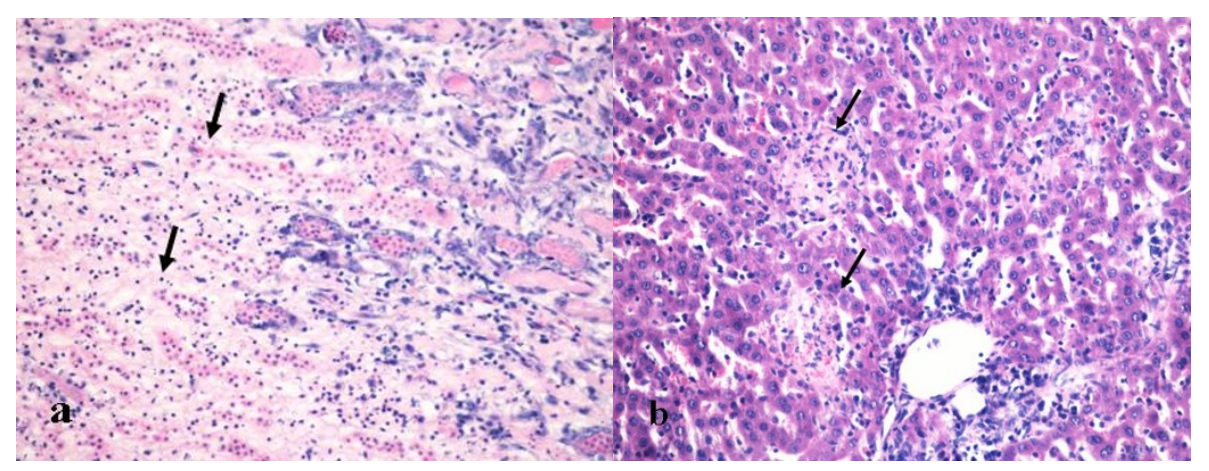

Figure 2 Histological examinations of the kidney and liver. Only one rat survived in the $15 \mathrm{mg} / \mathrm{kg}$ CsA group. The kidney and liver histology of the survived rat showed tissue necrosis: (a) Prominent tubular necrosis (black arrow) was found in the renal section; (b) Local necrosis (black arrow) was detected in the liver section (HE, Original magnification: $\times 200$ ).

volume between the control group and the two experimental groups treated with $1.5 \mathrm{mg} / \mathrm{kg}$ and $7.5 \mathrm{mg} / \mathrm{kg}$ CsA respectively (Table 3).

Compared with the control group, the middle femur shaft of the experimental group treated with $1.5 \mathrm{mg} / \mathrm{kg}$ or $7.5 \mathrm{mg} / \mathrm{kg}$ CsA showed no significant change in the value of any of the index of the bone biomechanical proprieties (Table 4).

Compared with the control group, the femoral neck of rats treated with $7.5 \mathrm{mg} / \mathrm{kg}$ CsA showed significantly lower values of the ultimate force, the ultimate stress and the Young modulus. However, the femoral neck of rats treated with $1.5 \mathrm{mg} / \mathrm{kg}$ CsA only showed a definite downward trend in all indices of the bone biomechanical proprieties, but the difference did not reach the statistical significance (Table 5).

\section{Effects of varying doses of CsA on the trabecular bone architecture}

The fourth lumbar vertebra displayed statistically significant lower values of the bone volume fraction, the trabecular thickness and the trabecular number between the control group and the $7.5 \mathrm{mg} / \mathrm{kg}$ CsA group. However, the fourth lumbar vertebra of the rats of the $1.5 \mathrm{mg} / \mathrm{kg}$ CsA group only showed statistically significant lower values of the bone volume fraction. Compared with the control group, the fourth lumbar vertebra of both experimental groups showed significantly higher values of the trabecular separation (Figure 4).
The right proximal tibia metaphysis displayed statistically significant lower values of the bone volume fraction, the trabecular thickness and the trabecular number between the control group and the $7.5 \mathrm{mg} / \mathrm{kg}$ CsA group. However, the right proximal tibia metaphysis of the rats of the $1.5 \mathrm{mg} / \mathrm{kg}$ CsA group only showed statistically significant lower values of the bone volume fraction and the trabecular number. Compared with the control group, the right proximal tibia metaphysis of both experimental groups showed significantly higher values of the trabecular separation (Figure 5).

\section{Effects of varying doses of CsA on the cortical thickness of the femoral shaft}

No significant change was observed in the cortical thickness of the middle femoral shaft between the control group and the two experimental groups (Figure 6).

\section{Discussion}

The patients who have undergone organ transplantation or acquired autoimmune disease always suffer from bone loss [21-24]. It is thus important to find out whether the long-term use of CsA will increase these patients' fracture risk. The present study showed that the CsA therapy at $7.5 \mathrm{mg} / \mathrm{kg}$ significantly reduced the BMD, the ultimate force and the ultimate stress of the lumbar vertebra and the proximal femur. The results indicated that the CsA therapy at $7.5 \mathrm{mg} / \mathrm{kg}$ can damage the mechanical properties and thus may increase the fracture risk of the lumbar

Table 1 Effects of CsA on the liver and kidney function

\begin{tabular}{ccccc}
\hline & ALT (U/L) & AST (U/L) & BUN (mmol/L) & Cr (umol/L) \\
\hline Baseline $(n=8)$ & $47.4 \pm 6.2$ & $174.8 \pm 34.7$ & $8.0 \pm 2.1$ & $79.4 \pm 12.3$ \\
Control $(n=12)$ & $50.0 \pm 6.2$ & $191.3 \pm 51.3$ & $8.4 \pm 1.8$ & $82.3 \pm 10.7$ \\
1.5 mg CsA $(n=11)$ & $45.3 \pm 8.3$ & $158.6 \pm 82.9$ & $9.3 \pm 1.5$ & $75.8 \pm 15.7$ \\
$7.5 \mathrm{mg} \mathrm{CsA}(n=9)$ & $72.5 \pm 26.3$ & $211.2 \pm 121.3$ & $11.8 \pm 5.0$ & $86.3 \pm 17.5$ \\
\hline
\end{tabular}

Data are expressed as means \pm SD. 

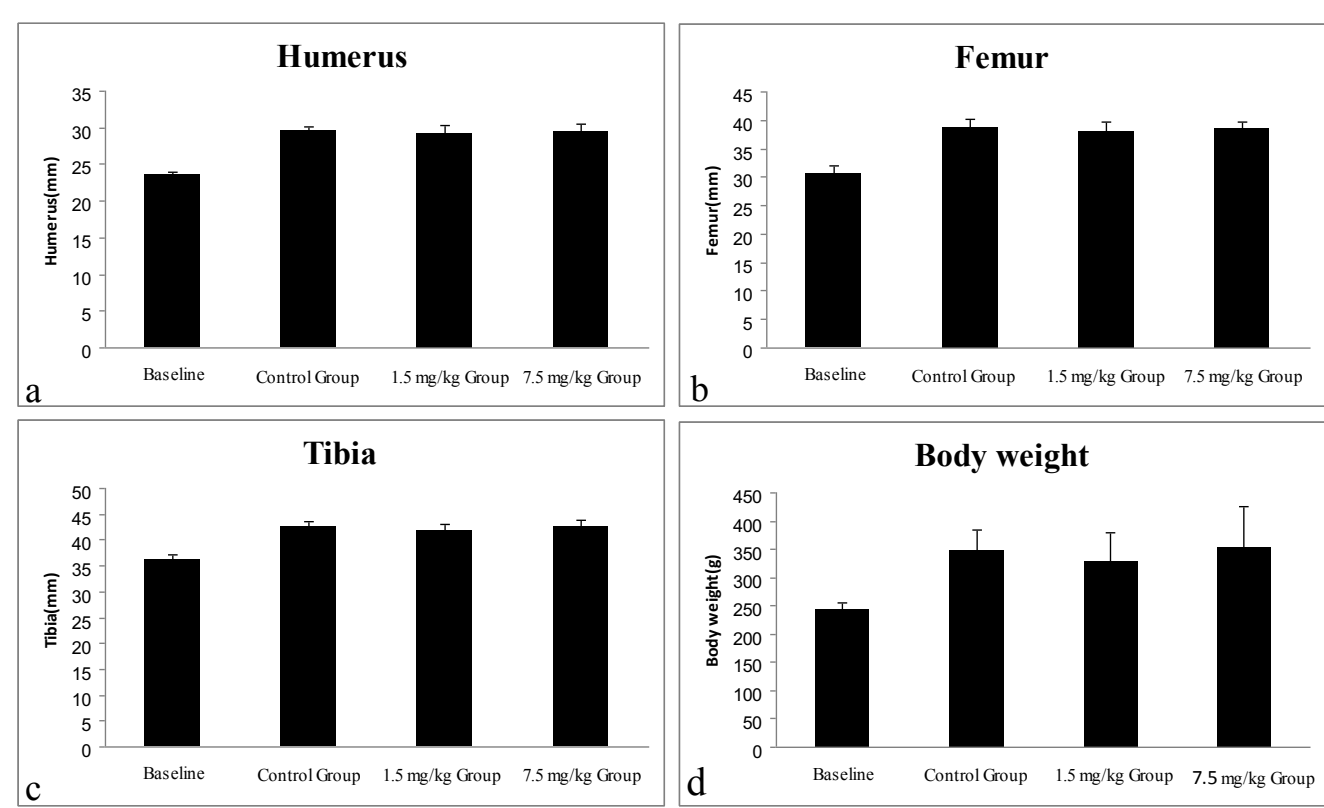

Figure 3 Effects of CsA on the bone length and the body weight. No significant change in the bone length or the body weight was observed among the control group, the $1.5 \mathrm{mg} / \mathrm{kg}$ CsA group and the $7.5 \mathrm{mg} / \mathrm{kg}$ CsA group: (a) The bone length of humerus; (b) The bone length of femur; (c) The bone length of tibia; (d) The body weight. Data are expressed as means (bars) \pm SD (error bar).

vertebra and the proximal femur. Such findings were consistent with those reported by Epstein et al [25], and may have important clinical implications.

Osteoporotic fracture is widely recognized as a public health threat because it is associated with increased risk of morbidity and mortality, and with significant health care costs [26,27]. Even in normal population, vertebral fractures and hip fracture are substantially associated with the mortality risk. Some recent studies reported that patients with osteoporotic vertebral fractures have a significant four-fold increase in mortality compared with patients without vertebral fractures [28], and that the mortality after a hip fracture remains significantly higher, being $11-23 \%$ at six months and $22-29 \%$ at one year from injury [29]. The present results also supported that if the CsA therapy is applied, the change of BMD of the vertebra and the hip should be monitored to predict the fracture risk.

The effects of CsA on the rat skeleton biomechanical properties closely bear upon both the dose and the

Table 2 Effect of CsA on the bone mineral density.

\begin{tabular}{|c|c|c|c|}
\hline & BMD $\left(\mathrm{g} / \mathrm{cm}^{2)}\right.$ & BMC (g) & Area $\left(\mathrm{cm}^{2)}\right.$ \\
\hline \multicolumn{4}{|l|}{ Lumbar Vertebra } \\
\hline Baseline $(n=8)$ & $0.237 \pm 0.018$ & $0.502 \pm 0.073$ & $2.124 \pm 0.287$ \\
\hline Control $(n=12)$ & $0.259 \pm 0.026$ & $0.609 \pm 0.107$ & $2.343 \pm 0.297$ \\
\hline $1.5 \mathrm{mg} \mathrm{CsA}(\mathrm{n}=11)$ & $0.204 \pm 0.030^{* *}$ & $0.473 \pm 0.091^{* *}$ & $2.325 \pm 0.260$ \\
\hline 7.5 mg CsA $(n=9)$ & $0.201 \pm 0.015^{* *}$ & $0.462 \pm 0.073 * *$ & $2.291 \pm 0.462$ \\
\hline \multicolumn{4}{|l|}{ Proximal Femur } \\
\hline Baseline $(n=8)$ & $0.245 \pm 0.038$ & $0.126 \pm 0.022$ & $0.513 \pm 0.028$ \\
\hline Control $(n=12)$ & $0.258 \pm 0.046$ & $0.139 \pm 0.029$ & $0.536 \pm 0.029$ \\
\hline $1.5 \mathrm{mg} \mathrm{CsA}(\mathrm{n}=11)$ & $0.181 \pm 0.036^{*}$ & $0.099 \pm 0.017^{* *}$ & $0.542 \pm 0.037$ \\
\hline 7.5 mg CsA $(n=9)$ & $0.171 \pm 0.039^{* *}$ & $0.092 \pm 0.025^{* *}$ & $0.530 \pm 0.027$ \\
\hline \multicolumn{4}{|l|}{ Middle Femur } \\
\hline Baseline $(n=8)$ & $0.298 \pm 0.075$ & $0.228 \pm 0.058$ & $0.762 \pm 0.021$ \\
\hline Control $(n=12)$ & $0.323 \pm 0.068$ & $0.258 \pm 0.052$ & $0.794 \pm 0.058$ \\
\hline $1.5 \mathrm{mg} \mathrm{CsA}(\mathrm{n}=11)$ & $0.311 \pm 0.066$ & $0.241 \pm 0.058$ & $0.771 \pm 0.052$ \\
\hline 7.5 mg CsA $(n=9)$ & $0.317 \pm 0.058$ & $0.243 \pm 0.045$ & $0.767 \pm 0.065$ \\
\hline
\end{tabular}

Data are expressed as means \pm SD. Compared with the control group, $\mathrm{p}<0.05 *, \mathrm{p}<0.01 * *$. 
Table 3 Effects of CsA on the mechanical parameters of the lumbar vertebra

\begin{tabular}{lcccc}
\hline & $\begin{array}{c}\text { Baseline } \\
(\mathbf{n}=\mathbf{8})\end{array}$ & $\begin{array}{c}\text { Control } \\
(\mathbf{n}=\mathbf{1 2})\end{array}$ & $\begin{array}{c}\mathbf{1 . 5} \mathbf{~ m g ~ C s A} \\
(\mathbf{n}=\mathbf{1 1})\end{array}$ & $\begin{array}{c}\mathbf{7 . 5} \mathbf{~ m g ~ C s A} \\
(\mathbf{n}=\mathbf{9})\end{array}$ \\
\hline Ultimate force $(\mathrm{N})$ & $143.7 \pm 24.4$ & $156.9 \pm 36.2$ & $119.9 \pm 34.7^{*}$ & $113.6 \pm 45.8^{*}$ \\
Stiffness (N/mm) & $688.2 \pm 209.7$ & $756.1 \pm 258.6$ & $698.7 \pm 298.3$ & $547.4 \pm 250.1$ \\
Energy absorption (mJ) & $29.8 \pm 14.5$ & $36.4 \pm 16.9$ & $24.8 \pm 11.7$ & $23.9 \pm 13.8$ \\
Ultimate stress (GPa) & $0.017 \pm 0.003$ & $0.017 \pm 0.004$ & $0.013 \pm 0.003^{*}$ & $0.011 \pm 0.005^{* *}$ \\
Young's modulus (Gpa) & $0.488 \pm 0.160$ & $0.444 \pm 0.130$ & $0.454 \pm 0.213$ & $0.333 \pm 0.147$ \\
Energy absorption (mJ/mm3) & $0.81 \pm 0.34$ & $0.77 \pm 0.44$ & $0.44 \pm 0.24^{*}$ & $0.34 \pm 0.28^{*}$ \\
\hline
\end{tabular}

Data are expressed as means \pm SD. Compared with the control group, $p<0.05 *$, p $<0.01 * *$.

duration of administration [10,11]. Goodman et al. found that the rats receiving $7.5 \mathrm{mg} / \mathrm{kg}$ CsA by daily oral gavages for 84 days showed osteopenia, and the rats receiving $1.5 \mathrm{mg} / \mathrm{kg}$ CsA were relatively bone sparing [8]. Our results showed that the CsA therapy at either $1.5 \mathrm{mg} / \mathrm{kg}$ or $7.5 \mathrm{mg} / \mathrm{kg}$ would damage the biomechanical properties of the lumbar vertebra, but neither dose of CsA therapy had a detrimental effect on the middle femur, furthermore, CsA therapy at $7.5 \mathrm{mg} / \mathrm{kg}$ but not at $1.5 \mathrm{mg} / \mathrm{kg}$ could damage the biomechanical properties of the proximal femur. Our findings importantly suggested that apart from the doses and duration of CsA therapy, the effects of CsA on skeletons were also closely related to the selection of anatomic sites, that is, the effects of CsA on skeleton are site-specific.

It is well known that the structural and metabolic heterogeneity is salient in the bones of rats. The cancellous bone is mainly located in axial bones with high turnover, while the cortical bone is mainly found in long bones with low turnover. Our results showed that compared with the control group, in the $7.5 \mathrm{mg} / \mathrm{kg}$ CsA therapy group the values of the bone volume fraction, the trabecular thickness, and the trabecular number of the lumbar vertebra were significantly reduced, whereas the value of the middle femur cortical thickness had no statistically significant change. The variations of these trabecular bone architectures were consistent with the changes of the BMD and biomechanical proprieties in the $7.5 \mathrm{mg} / \mathrm{kg}$ CsA therapy group. This is so because compared with the control group, the values of the $\mathrm{BMD}$, the ultimate force, the ultimate stress and the energy absorption per unit of bone volume of the lumbar vertebra in this therapy group were significantly reduced, whereas these values of the middle femur had no significant change. Our findings suggested that the lumbar vertebra contained predominantly cancellous bone and was prone to damage by the CsA, while the middle femur contained mainly cortical bone and was resistant to the deterioration of CsA. Our findings are in accordance with Movsowitz et al.'s report that CsA in the dose of $7.5 \mathrm{mg} / \mathrm{kg}$ could induce high turnover osteoporosis in rats, and the bone loss mainly occurred in cancellous bone [11]. Our findings are also in agreement with Klein et al.'s findings that CsA has little effect on cortical bone in rats [9].

CsA therapy is also associated with renal and hepatic impairment. In the $15 \mathrm{mg} / \mathrm{kg}$ CsA group only one rat survived. The kidney and liver histology of the survived rat showed extensive tissue necrosis, and the serum ALT, AST, BUN and Cr levels were respectively 2.5, 2.8, 3 , and 1.5 times of the averaged levels of the control group. The eleven rats may have died from the renal and hepatic impairment. In the $7.5 \mathrm{mg} / \mathrm{kg}$ CsA group, three rats died. Although we could not ascertain the exact cause for their death, these rats manifested the same cachexia characteristics before their death as the rats that died in the $15 \mathrm{mg} / \mathrm{kg}$ CsA group. We thus speculated that these rats may have also died from the renal and hepatic damage. Compared with the control group, no significant change in body weight and bone length was observed in either the $1.5 \mathrm{mg} / \mathrm{kg}$ or the 7.5 $\mathrm{mg} / \mathrm{kg}$ CsA therapy group. This may suggest that CsA

Table 4 Effects of CsA on the mechanical parameters of the middle femurs

\begin{tabular}{ccccc}
\hline & $\begin{array}{c}\text { Baseline } \\
(\mathbf{n}=\mathbf{8})\end{array}$ & $\begin{array}{c}\text { Control } \\
(\mathbf{n}=\mathbf{1 2})\end{array}$ & $\begin{array}{c}\mathbf{1 . 5} \mathbf{~ m g ~ C s A} \\
(\mathbf{n}=\mathbf{1 1})\end{array}$ & $\begin{array}{c}\mathbf{7 . 5} \mathbf{~ m g ~ C s A} \\
(\mathbf{n}=\mathbf{9})\end{array}$ \\
\hline Ultimate force $(\mathrm{N})$ & $112.7 \pm 19.1$ & $139.9 \pm 23.1$ & $128.6 \pm 22.1$ & $131.8 \pm 20.3$ \\
Stiffness (N/mm) & $317.6 \pm 87.4$ & $423.6 \pm 95.3$ & $347.5 \pm 96.4$ & $396.6 \pm 89.8$ \\
Energy absorption (mJ) & $20.1 \pm 4.5$ & $23.6 \pm 5.4$ & $24.7 \pm 5.4$ & $22.9 \pm 4.8$ \\
Ultimate stress (GPa) & $0.098 \pm 0.020$ & $0.101 \pm 0.016$ & $0.101 \pm 0.013$ & $0.096 \pm 0.016$ \\
Young's modulus (Gpa) & $9.9 \pm 2.5$ & $10.9 \pm 2.5$ & $9.2 \pm 1.5$ & $9.6 \pm 2.3$ \\
Energy absorption (mJ/mm3) & $0.49 \pm 0.08$ & $0.46 \pm 0.07$ & $0.53 \pm 0.14$ & $0.47 \pm 0.08$ \\
\hline
\end{tabular}

Data are expressed as means \pm SD. 
Table 5 Effects of CsA on the mechanical parameters of the femoral neck

\begin{tabular}{|c|c|c|c|c|}
\hline & $\begin{array}{c}\text { Baseline } \\
(\mathrm{n}=8)\end{array}$ & $\begin{array}{l}\text { Control } \\
(n=12)\end{array}$ & $\begin{array}{c}1.5 \mathrm{mg} C s A \\
(\mathrm{n}=11)\end{array}$ & $\begin{array}{c}7.5 \mathrm{mg} \mathrm{CsA} \\
(\mathrm{n}=9)\end{array}$ \\
\hline Ultimate force $(\mathrm{N})$ & $59.3 \pm 11.1$ & $70.4 \pm 7.2$ & $62.9 \pm 13.2$ & $54.9 \pm 14.8^{*}$ \\
\hline Stiffness (N/mm) & $108.4 \pm 23.1$ & $115.0 \pm 21.3$ & $103.3 \pm 20.2$ & $105.6 \pm 26.8$ \\
\hline Energy absorption (mJ) & $31.0 \pm 10.4$ & $30.3 \pm 7.0$ & $28.8 \pm 11.1$ & $27.9 \pm 15.5$ \\
\hline Ultimate stress (GPa) & $0.178 \pm 0.016$ & $0.196 \pm 0.010$ & $0.175 \pm 0.033$ & $0.135 \pm 0.026^{* *}$ \\
\hline Young's modulus (Gpa) & $2.25 \pm 0.47$ & $2.37 \pm 0.39$ & $2.08 \pm 0.54$ & $1.67 \pm 0.55^{* *}$ \\
\hline
\end{tabular}

Data are expressed as means \pm SD. Compared with the control group, $p<0.05 *, p<0.01 * *$

therapy at $1.5 \mathrm{mg} / \mathrm{kg}$ or $7.5 \mathrm{mg} / \mathrm{kg}$ has no inhibitory effect on the rat body and bone growth.

The exact mechanism that leads to the deterioration of skeletal biomechanical properties after CsA therapy remains inconclusive. In-vivo studies have demonstrated that the parameters of osteoblast and osteoclast function are both increased $[10,30]$, and our results have shown that CsA therapy at 1.5 and $7.5 \mathrm{mg} / \mathrm{kg}$ has no inhibitory effect on rat bone growth. Thus, it is unlikely that CsA has had a direct toxic effect on bone cells. In all likelihood, it maybe a combination of the two possibilities: 1) CsA may act directly on bone cells and affect their ability to secrete local autocrine factors or respond to systemic hormones. 2) CsA may have an indirect action on bone via their effects on the immune system [30,31]. Considering that the kidney is closely related to the bone mineral metabolism [32], we speculated that CsA therapy, especially in high dose, may have an indirect action on bone through a mechanism of abnormal mineral homeostasis due to impaired kidney function.

It has been reported that bone growth in rats slows drastically at 3 months of age and plateaus by 12 months [33], and that 3-month-old rats are more sensitive to the CsA therapy, apart from being in much better health condition and thus able to endure long-term CsA therapy $[34,35]$. In light of the previous reports, we used 3-month-old rat as the animal model in our present study. This animal model shares many characteristics with its human analog of post-transplantation osteoporosis, including a similar pattern of bone loss and a positive response to bisphosphonates therapy that is beneficial to humans [7]. However, the characteristics of bone remodeling in cortical bone in rats are not congruent to the human case [33]. The lack of intracortical bone remodeling in cortical bone may contribute to the resistance of the femur diaphysis to the damage of CsA
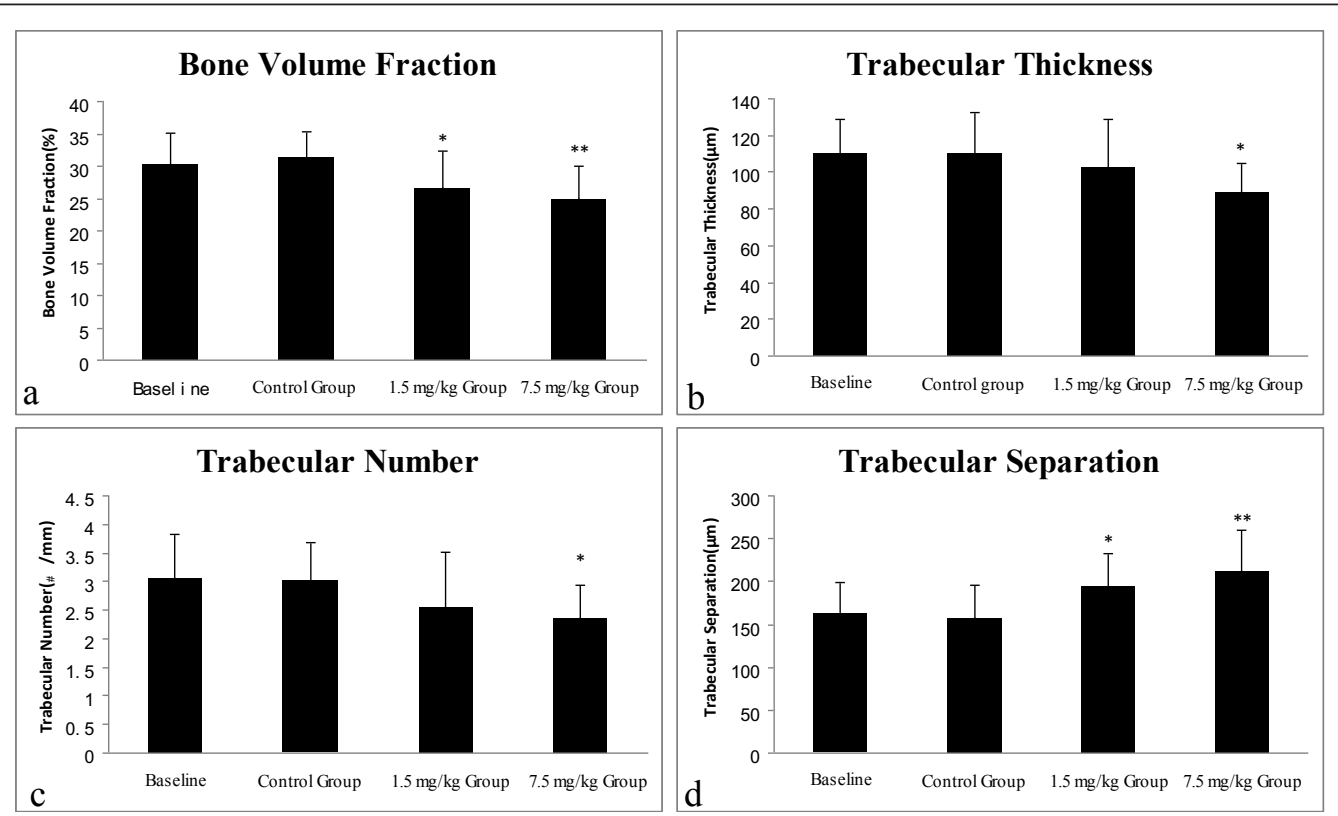

Figure 4 Effects of CsA on the lumbar vertebral trabecular bone architecture. Compared with the control group: (a) The values of the bone volume fraction were significantly decreased in the $1.5 \mathrm{mg} / \mathrm{kg}$ and the $7.5 \mathrm{mg} / \mathrm{kg}$ CsA group; (b) The values of the trabecular thickness were significantly decreased in the $7.5 \mathrm{mg} / \mathrm{kg}$ CsA group; (c) The values of the trabecular number were significantly decreased in the $7.5 \mathrm{mg} / \mathrm{kg}$ CsA group; (d) The values of the trabecular separation were significantly increased in the $1.5 \mathrm{mg} / \mathrm{kg}$ and the $7.5 \mathrm{mg} / \mathrm{kg}$ CsA group. Data are expressed as means (bars) \pm SD (error bar). Compared with the control group: $p<0.05 *, p<0.01 * *$ 

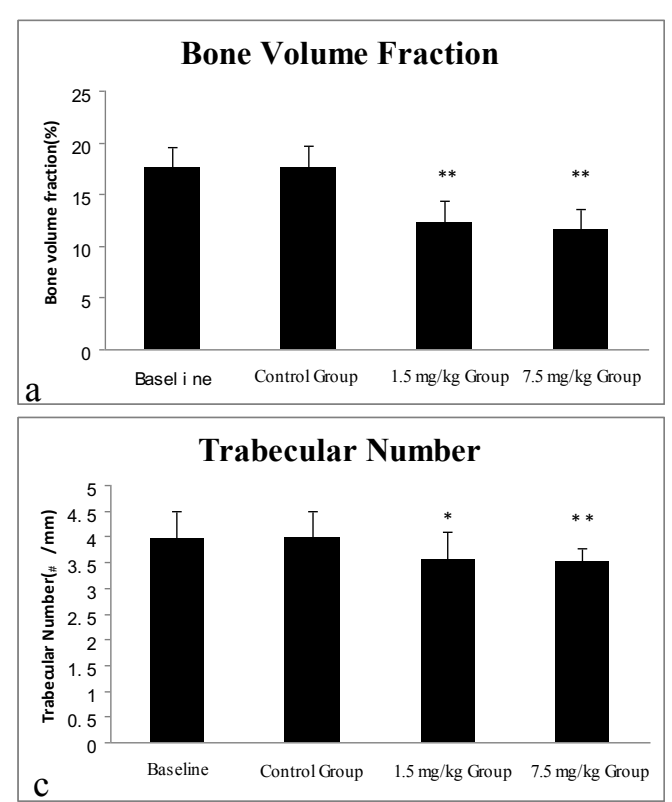
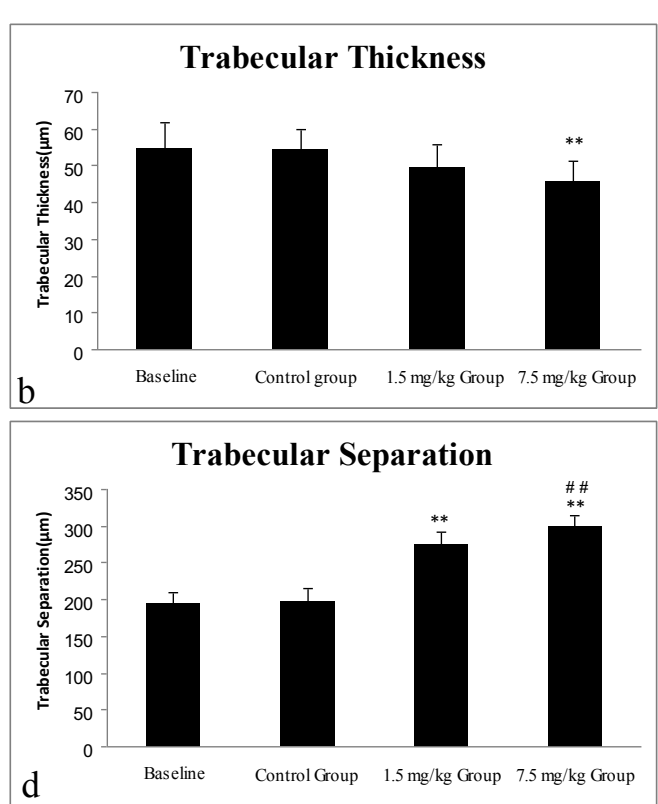

Figure 5 Effects of CsA on the proximal tibia metaphysis trabecular bone architecture. Compared with the control group: (a) The values of the bone volume fraction were significantly decreased in the $1.5 \mathrm{mg} / \mathrm{kg}$ and the $7.5 \mathrm{mg} / \mathrm{kg}$ CsA group; (b) The values of the trabecular thickness were significantly decreased in the $7.5 \mathrm{mg} / \mathrm{kg}$ group; (c) The values of the trabecular number were significantly decreased in the 1.5 $\mathrm{mg} / \mathrm{kg}$ and the $7.5 \mathrm{mg} / \mathrm{kg}$ CsA group; (d) The values of the trabecular separation were significantly increased in the $1.5 \mathrm{mg} / \mathrm{kg}$ and the $7.5 \mathrm{mg} /$ $\mathrm{kg}$ CsA group; Compared with the $1.5 \mathrm{mg} / \mathrm{kg}$ CsA group, the values of the trabecular separation were also significantly increased in the $7.5 \mathrm{mg} /$ $\mathrm{kg}$ CsA group. Data are expressed as means (bars) \pm SD (error bar). Compared with the control group: $p<0.05 *$, $p<0.01{ }^{*}$. Compared with the $1.5 \mathrm{mg} / \mathrm{kg}$ CsA group: $\mathrm{p}<0.05 \#, \mathrm{p}<0.01 \#$ \#.

therapy. Therefore this model should not be used to assess the response of cortical bone to the CsA therapy.

\section{Conclusions}

Long-term use of CsA can weaken the biomechanical properties and thus increase the fracture rate of the lumbar vertebra and the proximal femur. However, CsA therapy has less effect on the middle femur shaft. The effects of CsA on skeleton are site-specific.

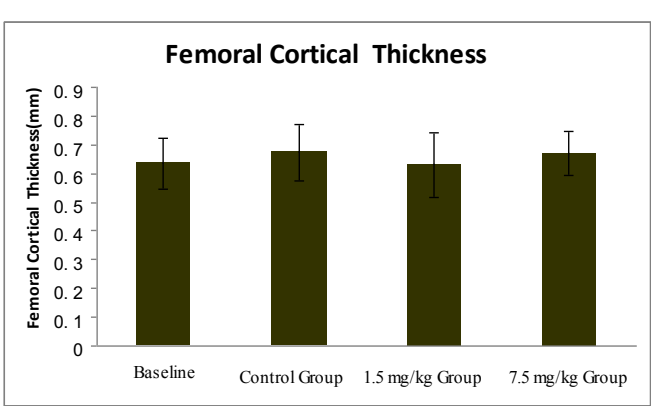

Figure 6 Effects of CsA on the femoral cortical thickness. No significant change in the femoral cortical thickness was observed among the control group, the $1.5 \mathrm{mg} / \mathrm{kg}$ CsA group and the 7.5 $\mathrm{mg} / \mathrm{kg}$ CsA group. Data are expressed as means (bars) \pm SD (error bar).
Acknowledgements

We thank Mr. Hanping Huang and Ms. Yifeng Zhang for providing skillful technical assistance.

\section{Authors' contributions}

YXC designed the study and drafted the manuscript. XZ, RZ and JFW performed the experimental work and the statistical analysis. All authors have read and approved the final manuscript.

\section{Competing interests}

The authors declare that they have no competing interests.

Received: 18 June 2011 Accepted: 24 October 2011

Published: 24 October 2011

\section{References}

1. Kulak CA, Borba VZ, Kulak Junior J, Campos DJ, Shane E: Posttransplantation osteoporosis. Ara Bras Endocrinol Metabol 2010, 54:143-149.

2. Ebeling PR: Approach to the patient with transplantation-related bone loss. J Clin Endocrinol Metab 2009, 94:1483-1490.

3. Aroldi A, Tarantino A, Montagnino G, Cesana B, Cocucci C, Ponticelli C: Effects of three immunosuppressive regimens on vertebral bone density in renal transplant recipients: a prospective study. Transplantation 1997, 63:380-386.

4. Westeel FP, Mazouz H, Ezaitouni F, Hottelart C, Ivan C, Fardellone P, Brazier M, EL Esper L, Petit J, Achard JM, Pruna A, Fournie A: Cyclosporine bone remodeling effect prevents steroid osteopenia after kidney transplantation. Kidney Int 2000, 58:1788-1796.

5. Leidig-Bruckner G, Hosch S, Dodidou P, Ritschel D, Conradt C, Klose C, Otto C, Lanqe R, Theilmann L, Zimmerman R, Pritsch M, Ziegler R: Frequency and predictors of osteoporotic fractures after cardiac and liver transplantation: a fellow-up study. Lancet 2001, 357:342-347.

6. Wada C, Kataoka M, Seto H, Hayashi N, Kido J, Shinohara Y, Nagata T: Highturnover osteoporosis is induced by cyclosporin A in rats. J Bone Miner Metab 2006, 24:199-205. 
7. Sass DA, Bowman AR, Yuan Z, Ma Y, Jee WS, Epstein S: Alendronate prevents cyclosporin A-induced osteopenia in the rat. Bone 1997, 21:65-70.

8. Goodman GR, Dissanayake IR, Sodam BR, Gorodetsky E, Lu J, Ma YF, Jee WS, Epstein S: Immunosuppressant use without bone loss-implications for bone loss after transplantation. J Bone Miner Res 2001, 16:72-78.

9. Klein L, Lemel MS, Wolfe MS, Shaffer J: Cyclosporin A dose not affect the absolute rate of cortical bone resorption at the organ level in the growing rat. Calcif Tissue Int 1994, 55:295-301.

10. Yeo H, Beck LH, McDonald JM, Zayzafoon M: Cyclosporin A elicits dosedependent biphasic effects on osteoblast differentiation and bone formation. Bone 2007, 40:1502-1516.

11. Movsowitz C, Epsten S, Fallon M, Ismail F, Thomas S: Cyclosporin-A in vivo produces severve osteopenia in the rat: effect of dose and duration of administration. Endocrinology 1988, 123:2571-2577.

12. Goodman GR, Dissanayake IR, Bowman AR, Pun S, Ma Y, Jee WS, Bryer HP, Epstein S: Transforming growth factor-beta administration modifies cyclosporine A-induced bone loss. Bone 2001, 28:583-588.

13. Bowman AR, Sass DA, Marshall I, Ma YF, Liang H, Jee WS, Epstein S: Raloxifene analog (LY117018 HCL) ameliorates cyclosporin A-induced osteopenia in oophorectomized rats. J Bone Miner Res 1996, 11:1191-1198.

14. Epstein S, Dissanayake IR, Goodman GR, Bowman AR, Zhou H, Ma Y, Jee WS: Effect of the interaction of parathyroid hormone and cyclosporine a on bone mineral metabolism in the rat. Calcif Tissue Int 2001, 68:240-247.

15. Buchinsky FJ, Ma Y, Mann GN, Rucinski B, Bryer HP, Romero DF, Jee WS, Epstein S: T lymphocytes play a critical role in the development of cyclosporin A-induced osteopenia. Endocrinology 1996, 137:2278-2285.

16. Jarvinen TLN, Sievanen H, Jokihaara J, Einhorn TA: Revival of bone strength: the bottom line. J Bone Miner Res 2005, 20:717-720.

17. Warren SB, Pelker RR, Friedlaender GE: Effect of short-term cyclosporin-A on biomechanical properties of intact and fractured bone in the rat. $J$ Orthop Res 1985, 3:96-100.

18. Earl F, Hsieh YD, Mao TK, Shen EC: A histomorphological investigation of the effect of cyclosprin on trabecular bone of the rat mandibular condyle. Arch Oral Biol 2001, 46:1105-1110.

19. Chen YX, Zheng X, Wang JF, Mao L, Ding YT: Effects of orthotopic liver transplantation in inbred rats on bone biomechanical properties. Transplant Proc 2010, 42:3809-3814.

20. Parfitt AM, Drezner MK, Glorieux FH, Kanis JA, Malluche H, Meunier PJ, Ott SM, Recker RR: Bone histomorphometry: standardization of nomenclature, symbols, and units. Report of the ASBMR Histomorphometry Nomenclature Committee. J Bone Miner Res 1987, 2:595-610.

21. Guanabens $N$, Cerda D, Monegal A, Pons F, Caballeria L, Peris P, Pares A: Low bone mass and severity of cholestasis affect fracture risk in patients with primary biliary cirrhosis. Gastroenterology 2010, 138:2348-2356.

22. Bechtold S, Putzker S, Birnbaum J, Schwarz HP, Netz H, Pozza RD: Impaired bone geometry after heart and heart-lung transplantation in childhood. Transplantation 2010, 90:1006-1010.

23. Resnick J, Gupta N, Wagner J, Costa G, Cruz RJ Jr, Martin L, Koritsky DA, Perera S, Matarese L, Eid K, Schuster B, Roberts M, Greenspan S, AbuElmaqd K: Skeletal integrity and visceral transplantation. Am J Transplant 2010, 10:2331-2340.

24. Pacifici R: The immune system and bone. Arch Broche Biophys 2010, 503:41-53.

25. Epstein s: Immunosuppressant drugs and bone disease: a clinician's perspective. J Clin Denitom 1998, 1:317-321.

26. Brennan SL, Henry MJ, Kotowicz MA, Nicholson GC, Zhang Y, Pasco JA: Incident hip fracture and social disadvantages in an Australian population aged 50 years or greater. Bone 2011, 48:607-610.

27. Leboime A, Confavreux CB, Mehsen N, Paccou J, David C, Roux C: Osteoporosis and mortality. Joint Bone Spine 2010, 77(Suppl 2):107-112.

28. Jalava T, Sarna S, Pylkkanen L, Mawer B, Kanis JA, Selby P, Davies M, Adams J, Francis RM, Robinson J, McCloskey E: Association between vertebral fracture and increased mortality in osteoporotic patients. $J$ Bone Miner Res 2003, 18:1254-1260.

29. Haleem S, Lutchman L, Mayahi R, Grice JE, Parker MJ: Mortality following hip fracture: trends and geographical variations over the last 40 years. Injury 2008, 39:1157-1163.
30. Cvetkovic M, Mann GN, Romero DF, Liang XG, Ma Y, Jee WS, Epstein S: The deleterious effects of long-term cyclosporine A, cyclosporine $G$, and FK506 one bone mineral metabolism in vivo. Transplantation 1994, 57:1231-1237.

31. Pacific R: The immune system and bone. Archives of Biochemistry and Biophysics. 2010, 503:41-53.

32. Mazzarerro S, Pasquali M, Pirro G, Rotondi S, Tartaglione L: The bone and the kidney. Archives of Biochemistry and Biophysics. 2010 503:95-102.

33. Grynpas MD, Chachra D, Lundon K: Bone quality in animal models of osteoporosis. Drug Development Research 2000, 49:146-158.

34. Del Pozo E, Lippuner K, Ruch W, Casez JP, Payne T, Mackenzie A, Jaeqer P: Different effects of cyclosporin $A$ on bone remodeling in young and adult rats. Bone 1995, 16(Suppl 4):271-275.

35. Katz I, Li M, Joffe I, Stein B, Jacobs T, Liang XG, Ke HZ, Jee W, Epstein S: The influences of age on cyclosprin A-induced alterations in bone mineral metabolism in the rat in vivo. J Bone Miner Res 1994, 9:59-66.

\section{Pre-publication history}

The pre-publication history for this paper can be accessed here: http://www.biomedcentral.com/1471-2474/12/240/prepub

doi:10.1186/1471-2474-12-240

Cite this article as: Chen et al:: Effects of cyclosporin-a on rat skeletal

biomechanical properties. BMC Musculoskeletal Disorders 2011 12:240.

\section{Submit your next manuscript to BioMed Central and take full advantage of:}

- Convenient online submission

- Thorough peer review

- No space constraints or color figure charges

- Immediate publication on acceptance

- Inclusion in PubMed, CAS, Scopus and Google Scholar

- Research which is freely available for redistribution

Submit your manuscript at www.biomedcentral.com/submit
C) Biomed Central 